\title{
METHANOLIC EXTRACTION OF FREE FERULIC ACID FROM OIL PALM
}

\section{NG MEI HAN*}

\begin{abstract}
Ferulic acid, a hydroxycinnamic acid, is known to exhibit anti-microbial, anti-inflammatory and antioxidant properties, making it a valuable compound for various applications. Study was conducted to investigate the extraction of free ferulic acid (ferulic acid that is not linked to lignin or other biopolymers) in the oil palm fruits, pressed fibre, empty fruit bunches (EFB), as well as its leaves, termed as frond. The extraction of free ferulic acid from these palm components was carried out using an alcoholic solution at various sample to solvent ratios. With the exception of fresh sterilised fruits, varying the sample to solvent ratio did not seem to have significant effect on the amount of ferulic acid extracted. Similarly, except for $E F B$ and sterilised fruits, the amount of ferulic acid extracted was not affected by the conditions of the samples (fresh or dried) prior to extraction. The free ferulic acid content in oil palm fruits, pressed fibre, EFB and oil palm frond ranged from 230-670 $\mathrm{mg} \mathrm{kg}^{-1}$.
\end{abstract}

\section{Keywords: extraction, ferulic acid, palm.}

Received: 14 July 2020; Accepted: 9 September 2020; Published online: 6 November 2020.

\section{INTRODUCTION}

Ferulic acid (4-hydroxy-3-methoxycinnamic acid) is a hydroxycinnamic acid that exists naturally in almost all plant cell walls, ranging from vegetables, spices and medicinal plants to agricultural residues (Mussatto, et al., 2007; Roby et al., 2013; Zhao et al., 2014). It has been known to exhibit anti-microbial, anti-inflammatory and antioxidant properties, making it a highly sought after compound in the medical, pharmaceutical and cosmetics industries (Bourne and Rice-Evans, 1998; Ou and Kwok, 2004; Mancuso et al., 2007; Neo et al., 2010; Aarabi et al., 2016). In addition, ferulic acid also plays a role in the production of biovanillin (bio-flavour) (TorresMancera et al., 2011). Food supplementation of ferulic acid with cucurmin can be used for the management of Alzheimer's disease through its oxidative damage and amyloid pathology reduction properties (Bourne and Rice-Evans, 1998; Kikuzaki et al., 2002; Ou and Kwok, 2004).

\footnotetext{
Malaysian Palm Oil Board,

6 Persiaran Institusi, Bandar Baru Bangi,

43000 Kajang, Selangor, Malaysia.

E-mail: meihan@mpob.gov.my
}

Concentrations of ferulic acid varies from $5 \mathrm{~g}$ $\mathrm{kg}^{-1}$ in wheat bran to $9 \mathrm{~g} \mathrm{~kg}^{-1}$ in sugar-beet pulp and $50 \mathrm{~g} \mathrm{~kg}^{-1}$ in corn kernel. Free and linked ferulic acid mostly present in leaves and seeds of plants. It is commonly present in cell walls as cross-links, such as arabinoxylans, pectin and xyloglucans (Torre et al., 2008; Aarabi et al., 2016; Truong et al., 2017).

The oil palm is a commodity plant widely cultivated in tropical countries such as Malaysia and Indonesia. It is mainly cultivated for its fruit bunches which yield oil. A number of beneficial phytonutrients have been identified to be present in palm oil, such as the carotenes, tocols (tocopherols and tocotrienols), as well as the coenzyme $\mathrm{Q}(\mathrm{Ng}$ et al., 2004; Ng and Choo, 2010; 2016). Besides the oil, the whole oil palm, including its by-products after oil extraction are utilised in various sectors, among others, renewable energy, cosmetics, animal feed, furniture and automobile. The presence of ferulic acid in oil palm/palm oil has been briefly investigated in the past, with attention given mostly to oil palm leaves and empty fruit bunches (EFB). As with other plants, the ferulic acid in oil palm consists of both free ferulic acid, and/or esters or linked to lignins 
and other biopolymers (Sun et al., 2001; Neo et al., 2008; 2010; Atawodi et al., 2011; Aanifah et al., 2014; Tang et al., 2014; Stavova et al., 2017).

Generally, oil palm milling starts with sterilisation of the oil palm bunches, followed by threshing of the bunch to strip the fruits, leaving behind the EFB. Thereafter, the fruits were pressed for its oil. Upon pressing, what remained of the fruit is called the palm pressed fibre. In other words, the EFB and pressed fibre are the leftovers or byproducts from oil palm milling. The EFB, pressed fibre, as well as other parts of the oil palm, such as the frond, are potential sources of ferulic acid.

Studies on the extraction of ferulic acid from oil palm milling by-products, such as the pressed fibre, EFB, and other palm biomass such as the oil palm frond are quite limited. Aanifah et al. (2014) carried out a study on the hydrolysis of ferulic acid from oil palm EFB using alkali while Tang et al. (2015) reported on the extraction of ferulic acid from oil palm EFB lignin. While these studies focused on the extraction of the covalently linked ferulic acid, there is no mention on the extraction of ferulic acid that is present in free form. Free ferulic acid is not soluble in water at room temperature but is highly soluble in methanol which made it a good solvent for extraction. Theoretically, larger amount of solvent will allow more solutes to dissolved in it, hence higher amount of solutes of interest can be extracted. However, in economic point of view, the use of large amount of solvent will incur higher cost. It is also difficult to handle such large amount of solvent. As such, keeping the amount of solvent used to a minimum while achieving highest yield is the ideal extraction scenario. As ferulic acid is highly soluble in methanol, the objective of this study is to determine the optimum solvent to sample ratio needed for the extraction of free ferulic acid from various parts of the oil palm using methanol and its analyses by supercritical fluid chromatography (SFC). This is also the first report on the analysis of ferulic acid in palm using SFC.

\section{MATERIALS AND METHODS}

\section{Materials}

Fresh unsterilised and sterilised oil palm fruits, EFB and palm pressed fibre were obtained from a palm oil mill in Negeri Sembilan, Malaysia. Oil palm frond was obtained from an oil palm plantation in Negeri Sembilan, Malaysia.

All solvents used were of analytical or chromatography grades, purchased from Merck (Darmstadt, Germany). Carbon dioxide $\left(\mathrm{CO}_{2}\right)$ used for SFC was purchased from Malaysian Oxygen (MOX). Ferulic acid standard (99\% purity) was purchased from Sigma-Aldrich (USA).

\section{Sample Pre-treatment}

Unsterilised oil palm fruits were peeled and the nuts were discarded, retaining the flesh (mesocarp). One gram of the peeled mesocarp was dried at $60^{\circ} \mathrm{C}$ overnight to remove moisture while the fresh mesocarp undergo extraction immediately. Palm pressed fibre, sterilised oil palm fruits, EFB and the oil palm fronds were weighed and dried in similar manner before extraction.

\section{Extraction of Free Ferulic Acid by Methanol}

One gram of fresh mesocarp (FM) were weighed in a round bottom flask. Methanol was added (ratio of FM to methanol, 1: 4, $\mathrm{g} \mathrm{ml}^{-1}$ ) and the mixture was refluxed in the dark at $60^{\circ} \mathrm{C}$ for $6 \mathrm{hr}$. Upon reflux, the mixture was cooled to room temperature. The mixture was then filtered to remove the solids. The filtrate were then rotavaped to near dryness. It was then centrifuged at $9000 \mathrm{rpm}$ for $2 \mathrm{~min}$. The precipitate was then collected while the supernatant was discarded. The precipitate were then made up to $5 \mathrm{ml}$ with methanol for SFC analyses.

Similar extraction procedure were then repeated for dried mesocarp (DM), fresh sterilised fruits (FSF), dried sterilised fruits (DSF), fresh frond (FF), dried frond (DF), fresh empty fruit bunch (FEFB), dried empty fruit bunch (DEFB), fresh palm pressed fibre (FPPF) and dried palm pressed fibre (DPPF) and the sample to methanol ratio was 1:6 and 1:8.

\section{SFC Analysis of Ferulic Acid Extracts}

Isocratic SFC analyses of the ferulic acid was carried out using a JASCO SFC system coupled with a photodiode array detector. Column used was RP C18, $5 \mu \mathrm{m}, 4.6 \times 250 \mathrm{~mm}$. The $\mathrm{CO}_{2}$ flow rate was $2.0 \mathrm{ml} \mathrm{min}{ }^{-1}$ with $0.1 \mathrm{ml} \mathrm{min}^{-1}$ methanol as modifier. The column temperature was set at $50^{\circ} \mathrm{C}$ and pressure $19 \mathrm{MPa}$. Injection volume was $20 \mu \mathrm{l}$. Identification of the ferulic acid peak was carried out with reference to authentic standard as well as comparing their respective UV spectra. Quantification of the ferulic acid was carried out by calibration with authentic standard.

All extraction and analyses were carried out in triplicates.

\section{RESULTS AND DISCUSSION}

The separation of ferulic acid standard and oil palm extracts by SFC is depicted in Figures 1-3. Due to the non-polar nature of supercritical carbon dioxide $\left(\mathrm{SC}-\mathrm{CO}_{2}\right), \mathrm{SFC}$, coupled with $\mathrm{CO}_{2}$ is rarely used for analyses of polar compounds. The separation of ferulic acid in the extracts by $\mathrm{SC}-\mathrm{CO}_{2}$ was made possible using a reversed stationary phase and 
the use of up to $5 \%$ methanol as entrainer. The ferulic acid was eluted in less than $5 \mathrm{~min}$. The calibration of ferulic acid in oil palm extracts were carried out with reference to authentic standard (Figure 3).

Alcohol extraction of free ferulic acid involved letting the free ferulic acid dissolved in the warm alcohol and concentrated it through removal of the alcohol thereafter where the ferulic acid, as well as other methanol soluble compounds, will crystallised in saturated solution. Under such circumstances, the amount of free ferulic acid extracted may be influenced by the condition of the samples (fresh or dried), as well as the amount of alcohol or solvent used for extraction. The amount of free ferulic acid in the extracts obtained from various parts of the oil palm under different sample to solvent (S/S) ratio are depicted in Table 1 and Figure 4. S/S ratio of less than 1:4 was not tested as the palm samples were not fully immersed in the small amount of solvent. With the exception of FSF and both FPPF and DPPF, the S/S ratio did not seem to have any significant effect on the extraction of ferulic acid. The amount of free ferulic acid extracted from FSF $\left(\sim 420 \mathrm{mg} \mathrm{kg}^{-1}\right)$, when $\mathrm{S} / \mathrm{S}$ ratio was $1: 8$ was about 1.5 times more as compared to $\mathrm{S} / \mathrm{S}$ ratio at $1: 4$ $\left(\sim 230 \mathrm{mg} \mathrm{kg}^{-1}\right)$ and 1:6 ( 251 $\left.\mathrm{mg} \mathrm{kg}^{-1}\right)$. Extraction of free ferulic acid from palm pressed fibre, both FPPF and DPPF, was found to be optimum when the S/S ratio was 1:6. Although theoretically higher amount of extraction solvent will allow more ferulic acid to be dissolved and hence extracted, the results from S/S ratio of 1:8 for FPPF and DPPF appeared to be the opposite. In their study, Tang et al. (2015) encountered lower amount of ferulic acid than expected from chemical and enzymatic extraction of ferulic acid from oil palm empty fruit bunch fibre lignin, but higher amount of vanillin. As reported by Tang et al. (2014), ferulic acid is a precursor to the bioconversion of vanillin. This could explain the lower amount of ferulic acid extracted in this study for FPPF and DPPF of S/S 1:8 whereby the ferulic acid was converted into vanillin. However, detailed study need to be further explored in this area to deduce such conclusion.

Higher concentrations of free ferulic acid are found in dried samples extracts, with the exception of dried unsterilised fruits (DUF) where slightly higher amounts of free ferulic acid was found in the fresh unsterilised fruits (FUF) extract compared to DUF. The moisture in fresh samples could have interfered with the solubility of free ferulic acid in methanol, hence, leading to lower amount of free ferulic acid extracted. During sterilisation, the oil palm fruits were heated with water to halt the enzyme activities which could deteriorate the quality of the extracted oil (Nokkaew and Punsuvon, 2014; Maya and Mohd Rozainee, 2013; Khanom et al., 2009). Excess water was typically drained after the completion of sterilisation but the sterilised oil palm fruits still retained some of the moisture. The same goes with the FEFB and DEFB samples which saw the ferulic acid extracted from DEFB to be about twice the amount in the FEFB extract. It should be noted that the EFB was obtained after the sterilisation process. The EFB received similar treatment as sterilised fruits, resulting in the retention of some moisture after sterilisation. The amount of free ferulic acid extracted from DEFB ranged from $490-531 \mathrm{mg} \mathrm{kg}^{-1}$ as compared to FEFB, 252-256 $\mathrm{mg} \mathrm{kg}^{-1}$, depending on the sample to solvent ratio.

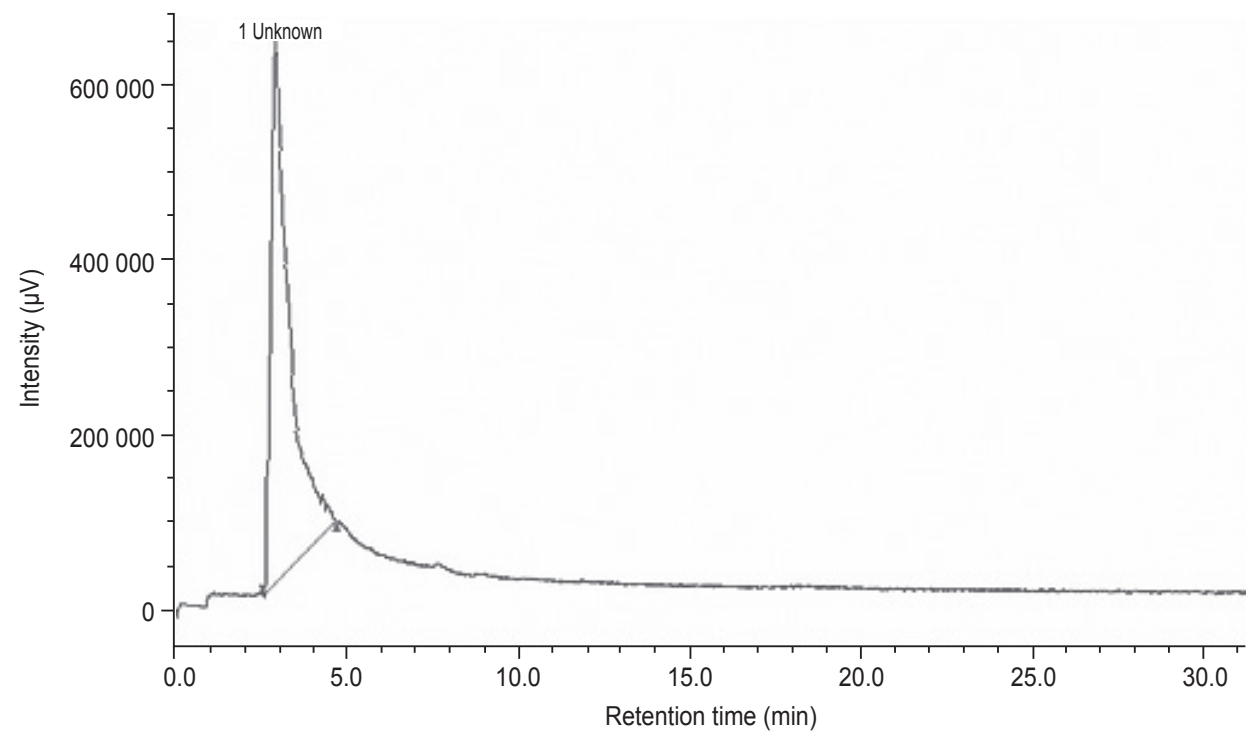

Figure 1. Supercritical fluid chromatogram of ferulic acid in dried palm pressed fibre (DPPF) extracted (sample to solvent, 1:6). 


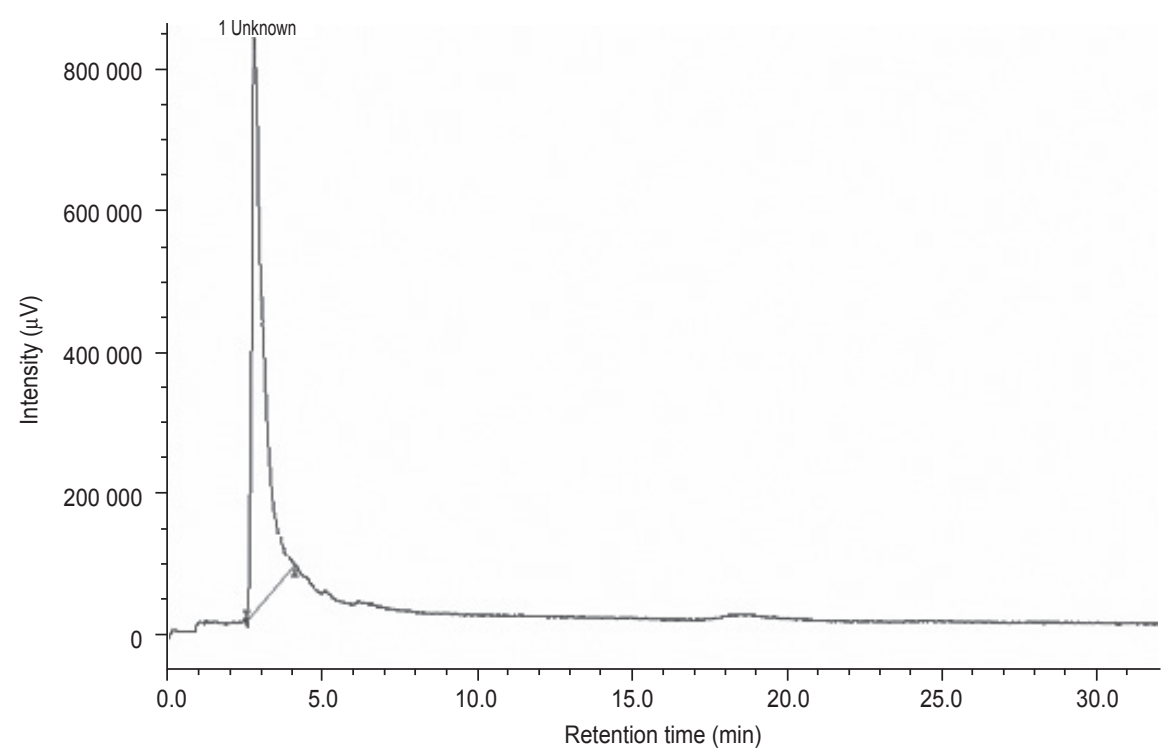

Figure 2. Supercritical fluid chromatogram of ferulic acid in fresh palm frond extracted (sample to solvent, 1:8).

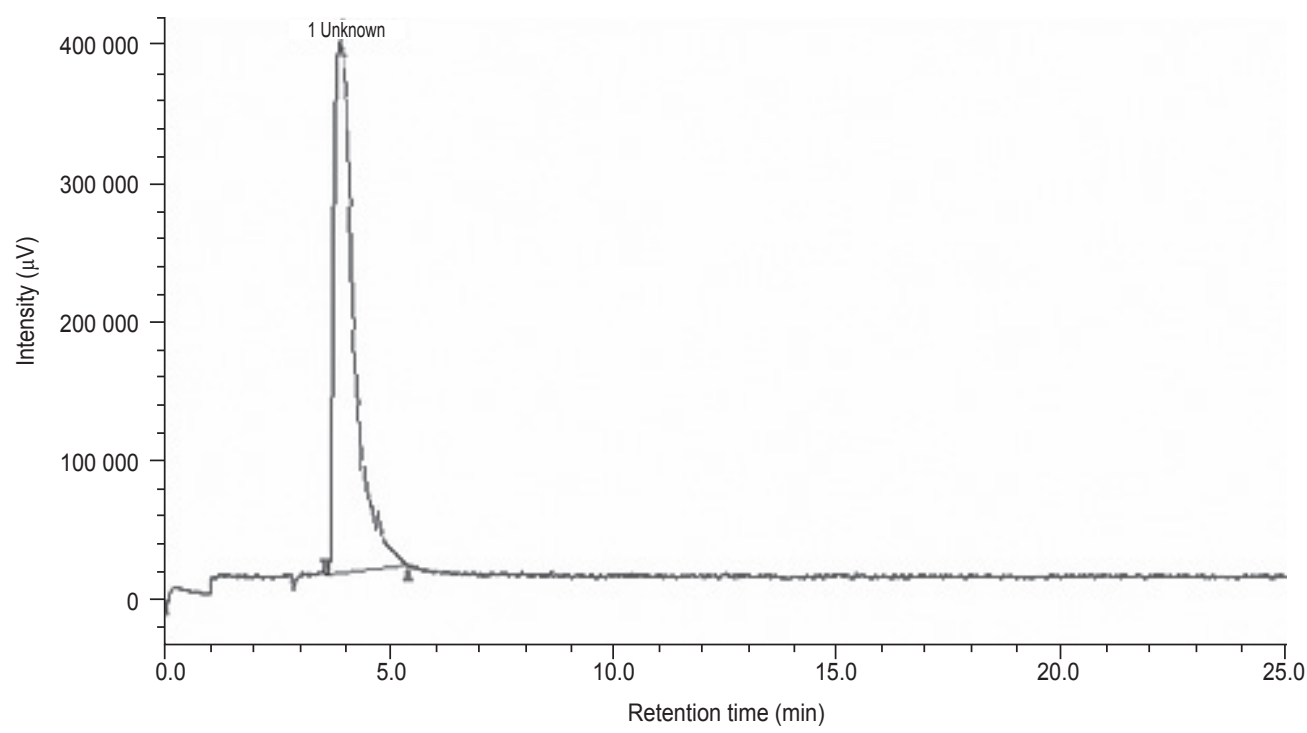

Figure 3. Supercritical fluid chromatogram of ferulic acid standard.

TABLE 1. FREE FERULIC ACID EXTRACTED FROM OIL PALM UNDER DIFFERENT SAMPLE TO SOLVENT RATIO

\begin{tabular}{llccc}
\hline \multirow{2}{*}{ Sample } & & \multicolumn{3}{c}{ Ferulic acid concentration ${\text { (mg } \mathbf{~ k g}^{-1} \text { ) extracted under }}^{\text {sample to solvent ratio }}$} \\
\cline { 3 - 5 } & & $\mathbf{1 : 4}$ & $\mathbf{1 : 6}$ & $\mathbf{1 : 8}$ \\
\hline \multirow{2}{*}{ Unsterilised fruits } & Fresh (FUF) & $250 \pm 3$ & $252 \pm 5$ & $255 \pm 8$ \\
& Dried (DUF) & $245 \pm 4$ & $262 \pm 1$ & $250 \pm 7$ \\
Sterilised fruits & Fresh (FSF) & $230 \pm 2$ & $251 \pm 6$ & $420 \pm 4$ \\
& Dried (DSF) & $604 \pm 8$ & $628 \pm 8$ & $668 \pm 12$ \\
Palm pressed fibre & Fresh (FPPF) & $280 \pm 6$ & $352 \pm 3$ & $284 \pm 4$ \\
& Dried (DPPF) & $291 \pm 6$ & $514 \pm 8$ & $281 \pm 9$ \\
\multirow{3}{*}{ Ealm frond } & Fresh (FPF) & $250 \pm 7$ & $257 \pm 3$ & $256 \pm 8$ \\
& Dried (DPF) & $241 \pm 8$ & $254 \pm 4$ & $270 \pm 10$ \\
& Fresh (FEFB) & $252 \pm 4$ & $256 \pm 4$ & $253 \pm 6$ \\
& Dried (DEFB) & $490 \pm 8$ & $531 \pm 7$ & $497 \pm 2$ \\
\hline
\end{tabular}




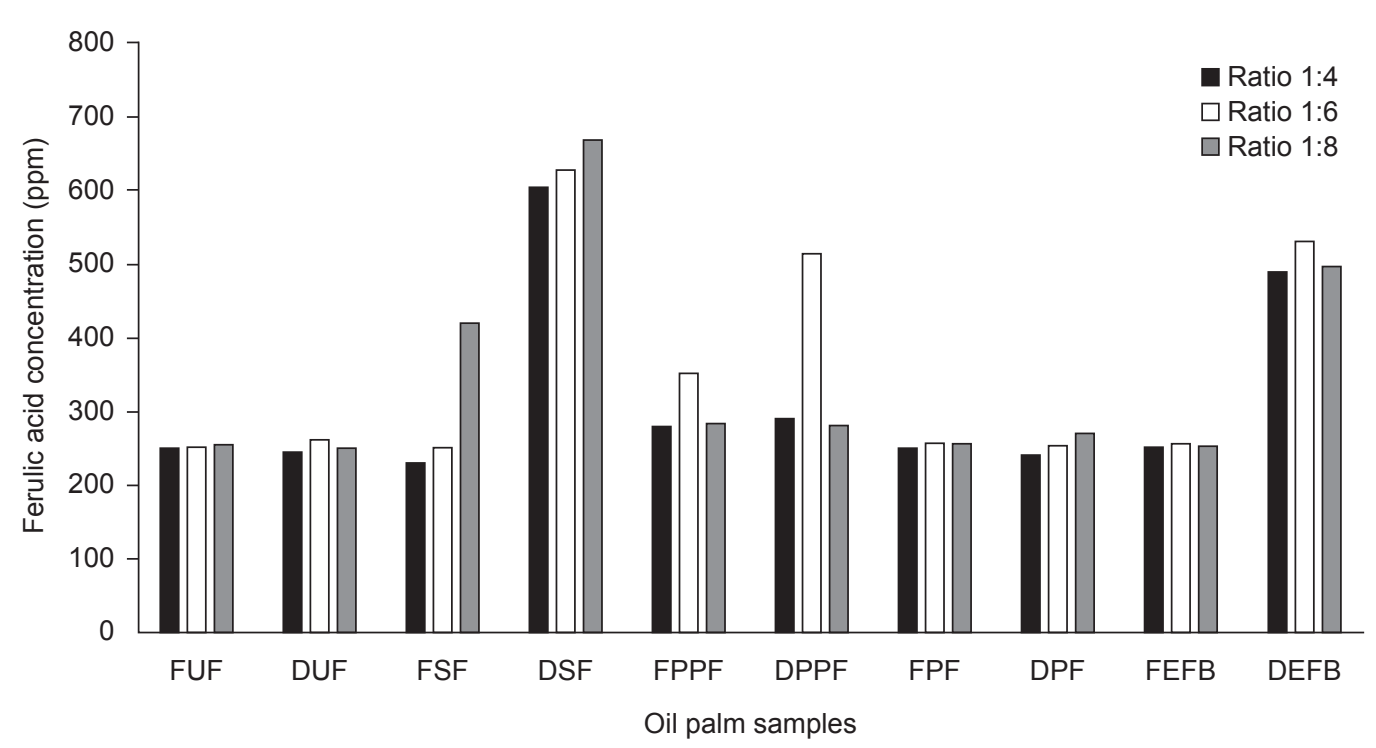

Note: FUF - fresh unsterilised fruits; DUF - dried unsterilised fruits; FSF - fresh sterilised fruits; DSF - dried sterilised fruits; FPPF - fresh palm pressed fibre; DPPF - dried palm pressed fibre; FPF - fresh palm frond; DPF - dried palm frond; FEFB - fresh empty fruit bunch; DEFB - dried empty fruit bunch.

Figure 4. Composition of ferulic acid extracted from various oil palm biomass.

Besides the aforementioned scenarios, the $\mathrm{S} / \mathrm{S}$ ratio as well as the conditions of the samples prior to extraction did not seem to have a significant effect on the extraction of free ferulic acid for the same type of sample. At $241-270 \mathrm{mg} \mathrm{kg}^{-1}$, the amount of free ferulic acid in both dried and fresh palm frond (DPF and FPF) are comparable.

There was however, a significant difference in the amount of ferulic acid extracted from sterilised and unsterilised fruits for both types of sample conditions, fresh and dried. At $S / S$ ratio of $1: 8$, the amount of free ferulic acid extracted from FSF at $420 \mathrm{mg} \mathrm{kg}^{-1}$, was almost doubled that of FUF at $255 \mathrm{mg} \mathrm{kg}^{-1}$. The difference was even more significant between DUF, $250 \mathrm{mg} \mathrm{kg}^{-1}$ and DSF, $668 \mathrm{mg} \mathrm{kg}^{-1}$. It is believed that the sterilisation process contributed to this difference. Besides halting the enzymatic activities, sterilisation also caused the oil palm fruits to be softened, hence, leading the mesocarp to be more readily penetrated by the extracting solvent, resulting in higher solubility of free ferulic acid, which then gave rise to higher yield (Nokkaew and Punsuvon, 2014; Maya and Mohd Rozainee, 2013; Khanom et al., 2009).

This study focused on the extraction of ferulic acid in free form from various parts of the oil palm. Ferulic acid that is covalently linked to lignin and other biopolymers or as ester cross-links with polysaccharides in the cell wall cannot be extracted using the same method. Cleavages of the covalent bonds need to be first carried out before these ferulic acid can be obtained. Some methods reported that were able to free these covalently linked ferulic acid are alkaline hydrolysis, enzymatic extraction, and more recently, the use of deep eutectic solvents and / or ionic liquids (Liu and Wang, 2011, 2012; Torre et al., 2008; Truong et al., 2017; Tang, et al., 2015). As reported by Aanifah et al. (2014), as much as 3800$4200 \mathrm{mg} \mathrm{g}^{-1}$ ferulic acid can be extracted from the palm EFB by way of alkaline hydrolysis, as compared to $\sim 500 \mathrm{mg} \mathrm{kg}^{-1}$ from methanol extraction in this study. Although the yield of ferulic acid extracted from alkaline hydrolysis is higher, nevertheless, alcohol extraction offers a simple and rapid method to extract the ferulic acid in its free form, where they can be readily used as raw material for production of further downstream products.

\section{CONCLUSION}

The oil palm biomass, especially the EFB, are good sources of free ferulic acid. The amount of free ferulic acid extracted from the palm pressed fibre and EFB are comparable to its amount in the oil palm fruits. This suggests that that the milling process did not significantly affect the ferulic acid content in palm. This study showed that warm methanol is sufficient to extract free ferulic acid from the by-products of the oil palm milling as well as various parts of the oil palm.

\section{ACKNOWLEDGEMENT}

The author wishes to thank the Director-General of MPOB for the funding of this study as well as permission to publish this article. 


\section{REFERENCES}

Aanifah, F J M; Phang, L Y; Wasoh, $\mathrm{H}$ and Abd Aziz, $S$ (2014). Effect of different alkaline treatment on the release of ferulic acid from oil palm empty fruit bunch fibres. J. Oil Palm Res., 26(4): 321-331.

Aarabi, A; Honarvar, M; Mizani, M; Haghihian, H and Gerami, A (2016). Extraction and purification of ferulic acid as an antioxidant from sugar beet pulp by alkaline hydrolysis. Ital. J. Food Sci., 28: 362-375. DOI: 10.1007/s11694-015-9274-z.

Atawodi, S E; Yusufu, L; Akawodi, J; Asuku, O and Yakubu, O (2011). Phenolic compounds and antioxidant potential of Nigerian red palm oil (Elaeis guineensis). Int. J. Biol., 3(2): 153-161. DOI: 10.5539/ ijb.v3n2p153.

Bourne, L C and Rice-Evans, C (1998). Bioavailability of ferulic acid. Biochem. Biophys. Res. Commun., 253(2): 222-227. DOI: 10.1006/ bbrc.1998.9681.

Khanom, S; Mohd Ali Hassan, Suraini, A A and Shirai, Y (2009). Effect of palm oil mill sterilization process on the physicochemical characteristics and enzymatic hydrolysis of empty fruit bunch. Asian J. Biotechnol., 1(2): 57-66.

Kikuzaki, H; Hisamoto, M; Arose, K; Akiyama, K and Taniguchi, H (2002). Antioxidant properties of ferulic acid and its related compounds. J. Agric. Food Chem., 50(7): 2161-2168. DOI: 10.1021/jf011348w.

Liu, S X and Wang, B (2011). Preliminary research on extract ferulic acid from wheat bran by ultrasonicassisted alkaline-alcohol hydrolysis. Adv. Mat. Res., 361-363: 753-758.

Liu, S X and Wang, B (2012). Purification of ferulic acid from wheat by ultrafiltration technology. Adv. Mat. Res., 524-527: 2294-2297.

Mancuso, C; Scapagini, G; Currŏ, D; Giuffrida Stella, A M; De Marco, C; Butterfield, D A and Calabree, V (2007). Mitochondrial dysfunction, free radical generation and cellular stress response in neurodegenerative disorders. Front. Biosci., 1(12): 1107-1123. DOI: $10.2741 / 2130$.

Maya, S and Mohd Rozainee, T (2013). Enzymatic destruction kinetics of oil palm fruits by microwave sterilization. Int. J. Chem. Eng. Appl., 4(3): 129-133.

Mussatto, S I; Dragone, G and Roberto, I C (2007). Ferulic and p-coumaric acids extraction by alkaline hydrolysis of brewer's spent grain. Ind. Crops Prod., 25(2): 231-237. DOI: 10.1016/j.indcrop.2006.11.001.
Neo, Y P; Ariffin, A; Tan, C P and Tan, Y A (2008). Determination of oil palm fruit phenolic compounds and their antioxidant activities using spectrophotometric methods. Int. J. Food Sci. Technol., 43(10): 1832-1837. DOI: 10.1111/j.13652621.2008.01717.x.

Neo, Y P; Ariffin, A; Tan, C P and Tan, Y A (2010). Phenolic acid analysis and antioxidant activity assessment of oil palm (E. guineensis) fruit extracts. Food Chem., 122(1): 353-359. DOI: 10.1016/j. foodchem.2010.02.046.

$\mathrm{Ng}, \mathrm{M} \mathrm{H}$ and Choo, Y M (2010). Determination of antioxidants in oil palm leaves (Elaeis guineensis). Am. J. Appl. Sci., 7(9): 1243-1247. DOI: 10.3844/ ajassp.2010.1243.1247.

Ng, M H and Choo, Y M (2016). Improved method for the qualitative analyses of palm oil carotenes using UPLC. J. Chromatogr. Sci., 54(4): 633-638. DOI: 10.1093 / chromsci/bmv241.

Ng, M H; Choo, Y M; Ma, A N; Chuah, C H and Mohd Ali Hashim (2004). Isolation of palm tocols using supercritical fluid chromatography. J. Chromatogr. Sci., 42(10): 536-539. DOI: 10.1093/ chromsci / 42.10 .536 .

Nokkaew, R and Punsuvon, V (2014). Sterilization of oil palm fruits by microwave heating for replacing steam treatment in palm oil mill process. Adv. Mat. Res., 1025-1026: 470-475.

Ou, S and Kwok, K C (2004). Ferulic acid: Pharmaceutical functions, preparation and applications in foods. J. Sci. Food Agric., 84: 12611269. DOI: 10.1002 / jsfa.1873.

Roby, M H H; Sarhan, M A; Selim, K A H and Khalel, K I (2013). Evaluation of antioxidant activity, total phenols and phenolic compounds in thyme (Thymus vulgaris L.), sage (Salvia officinalis L.), and marjoram (Origanum majorana L.) extracts. Ind. Crops Prod., 43: 827-831. DOI: $10.1016 /$ j.indcrop.2012.08.029.

Stavova, E; Porizka, J; Stursa, V; Enev, V and Divis, P (2017). Extraction of ferulic acid from wheat bran by alkaline hydrolysis. MendelNet, 2017: 574-579.

Sun, R C; Sun, XF and Zhang, S H (2001). Quantitative determination of hydroxycinnamic acids in wheat, rice, rye, and barley straws, maize stems, oil palm frond fiber and fast-growing poplar wood. J. Agric. Food Chem., 49(11): 5122-5129. DOI: 10.1021 /jf010500r.

Tang, P L; Hassan, O; Jamaliah, M J; Wan Mustapha, W A and Maskat, M Y (2014). Fibrous agricultural biomass as a potential source for bioconversion 
to vanillic acid. Int. J. Polym. Sci.,: 7-8. DOI: $10.1155 / 2014 / 509035$.

Tang, P L; Osman, H; Mohamad Yusof, M and Khairiah, B (2015). Production of monomeric aromatic compounds from oil palm empty fruit bunch fiber lignin by chemical and enzymatic methods. Biomed. Res. Int., 2015: 891539.

Torre, P; Aliakbarian, B; Rivas, B; Domínguez, J and Converti, A (2008). Release of ferulic acid from corn cobs by alkaline hydrolysis. Biochem. Eng. J., 40: 500506.

Torres-Mancera, M T; Cordova, J; Rodriguez-Serrano, G; Roussos, S; Ramiez-Coronel, A; Favela-Torres, E and Saucedo-Castaňedfa, G (2011). Enzymatic extraction of hydroxycinnamic acids from coffee pulp. Food Technol. Biotechnol., 49(3): 369-373.

Truong, H T; Do Van, M; Duc Huynh, L; Thi Nguyen, L; Do Tuan, A; Le Xuan Thanh, T; Duong Phuoc, H; Takenaka, N; Imamura, K and Maeda, Y (2017). A method for ferulic acid production from rice bran oil soapstock using a homogenous system. Appl. Sci., 7: 796.

Zhao, S; Yao, S; Ou, S; Lin, J; Wang, Y; Peng X; Li $A$ and Yu, B (2014). Preparation of ferulic acid from corn bran: Its improved extraction and purification by membrane separation. Food Bioprod. Process., 92(3): 309-313. DOI: 10.1016/j.fbp.2013.09.004. 